\title{
Effect of additional load on angular parameters during gait and balance in children with hemiparesis - Cross sectional study
}

\author{
Siddharth S. Mishra ${ }^{1}$, Rashmi Potdar ${ }^{2}$ \\ 1 MGM Hospital Department of Neuro-Physiotherapy and College of Physiotherapy Navi, Mumbai, Affiliated to \\ Maharashtra University of Health Sciences (MUHS) Nasik, India; ${ }^{2}$ MGM Hospital and College of Physiotherapy Navi \\ Mumbai, affiliated to Maharashtra University of Health Sciences (MUHS) Nasik, India
}

\begin{abstract}
Study aim: To study the effect of additional load over ankle and knee joints on angular parameters during gait and balance in children with hemiparesis.

Material and methods: 10 children with hemiparesis were recruited and stratified into 2 chronological age groups: group A (4-8 years) and group B (9-12 years). Additional loads of $0.7 \mathrm{~kg}$ and $1.1 \mathrm{~kg}$ were placed on the affected and non-affected lower limb at the ankle and knee joint for group A and group B respectively. Angular parameters during gait were assessed using Kinovea software (version 0.8.15) and balance using the Pediatric Balance Scale.

Results: Application of additional load of $0.7 \mathrm{~kg}$ over the non-affected leg knee joint is able to produce significant changes in ankle joint angles $(\mathrm{p}<0.05)$ at initial contact and knee joint angles at heel-off $(\mathrm{p}<0.05)$, toe-off $(\mathrm{p}<0.001)$, acceleration $(\mathrm{p}<0.05)$ and deceleration $(\mathrm{p}<0.05)$ phases of gait and balance in group A, whereas on application of additional load of $1.1 \mathrm{~kg}$ over the affected leg at the ankle joint significant improvement in knee joint angles at initial contact $(\mathrm{p}<0.001)$ and the deceleration $(\mathrm{p}<0.05)$ phase of gait in group B was observed. There was significant improvement in the Pediatric Balance Scale score in both groups $(\mathrm{p}<0.05)$.

Conclusions: Additional load over knee and ankle joints of the affected and non-affected leg showed more improvement in angular parameters during gait and balance in younger children with hemiparesis than older children, as they present an immature form of gait that can be modified, corrected and brought back to a normal angle.
\end{abstract}

Key words: Balance - Angular Parameter - Joint Angles - Hemiparesis - Children - Additional load

\section{Introduction}

Hemiparesis is a weakness of one side of the body. Hemiparesis is seen in conditions such as infective endocarditis, stroke due to birth trauma, congenital brain malformations, e.g. cerebral agenesis, cerebral palsy, cerebellar abscess, head injury, meningitis, Moya-Moya disease and many more. Prevalence of hemiplegic children in India is 1.2 to 2.7 per 100000 [21]. Normal gait and balance mechanisms include proper coordination of kinematic and kinetic components [28], reactive and proactive postural control $[1,2]$, and complex interaction of the sensory and perceptual system, motor systems and high level central nervous system to execute a plan of action [38]. Decreased muscle strength, abnormal body posture and gait, and poor static and dynamic balance are commonly seen in these children. Also reduced or absent dorsiflexion and poor knee joint range amplitude during the swing phase of the gait cycle are commonly observed [2]. Disruption of central sensorimotor processing, uneven distribution of weight [22] and increased postural sway contribute to the poor equilibrium state in these children [7].

Several studies have reported that children with hemiparetic cerebral palsy demonstrate poor ankle control causing reduced transverse rotation of the body for postural stability, delay in motor activity, abnormal timing of movement strategies, biomechanical constraints, poor cognitive processing, and perception of verticality resulting in balance impairments. [7, 9, 10, 12]

Studies also suggest that application of loaded weight on lower limb using the treadmill has a significant effect on 
balance and gait parameters in adult stroke patients [20, 40]. Studies have shown that application of additional waist load and customized load in both lower limbs have shown improvement of angular parameters of gait in children with cerebral palsy [31, 40]. There were gaps in research reporting evidence on application of non-designed constant load to different segments of one lower limb and its effect on angular parameters of gait and balance in hemiparetic children. Hence this study aimed to explore the effect of additional load over ankle and knee joints on angular parameters of gait and balance in children with hemiparesis.

\section{Materials and methods}

\section{Participants}

The study was conducted after obtaining ethical approval from the institutional ethical review board. Informed consent was sought from parents. 10 hemiparetic children were recruited from 2 tertiary health care centres and 2 children's rehabilitation centres through convenient sampling. They were stratified into 2 chronological age groups: Group A: age 4-8 years and Group B: 9-12 years. The inclusion criteria were: hemiparetic children able to walk 10 meters without assistance, gained ability to walk since past 1 year and Gross Motor Function Classification Scale (GMFCS) level I and II, whereas noncooperative subjects and parents, and subjects having any other chronic systemic diseases, musculoskeletal diseases, or cardio-pulmonary diseases were excluded (Table 1). General instructions and activity demonstration were given in the language best understood by them. Participants were advised to wear minimum clothing, maintain proper hydration and activity was performed off shoe on the day of assessment. 5 circular shaped markers of 2-inch diameter were placed on the lower limb of each participant: 1) $10 \mathrm{~cm}$ above knee joint line over lateral and medial sides at mid-thigh level, 2) lateral and medial knee joint line, 3) $5 \mathrm{~cm}$ below knee joint line lateral and medial side at mid-calf level, 4) lateral and medial malleolus and 5) first and fifth metatarsal heads [18, 32].

Camera placement: one camera (resolution: 20-megapixel Sony Exmor IMX376K f/1.7 480fps at 720p) was placed on a portable tripod perpendicular to the centre of pathway at a distance of 4 feet from the walking path and 2 feet above the ground, stipulating the 3-meter frame area that covered the gait sagittal view of gait (Figure 1) $[25,35]$. The position of the camera was placed keeping constant distance. Observations were in line with the camera lens and tripod stand ensuring steadiness that helped in minimizing parallax error with $2 \mathrm{D}$ analysis in the sagittal plane. $[11,22,23]$.

Additional loads of $0.7 \mathrm{~kg}$ and $1.1 \mathrm{~kg}$ were calibrated using the standardized procedure that includes the eccentricity test and reliability test retest. Application of additional load over the waist more than $10 \%$ of body weight causes faults in angular parameters of gait in cerebral palsy children [44], so approximately $3 \%(0.7 \mathrm{~kg})$ and $5 \%$ $(1.1 \mathrm{~kg})$ of body weight were considered in our study for younger and older participants respectively. All participants walked the stipulated 3-meter distance without any additional load; a video three trials was uploaded and average baseline angular parameters were recorded and the 14 functional task Pediatric Balance Scale was performed by each participant, and baseline score was recorded.

For angular parameters during gait: Group A received an additional load of $0.7 \mathrm{~kg}$ that was applied on the affected side lower limb at the ankle joint and participants were made to walk a 3-meter distance followed by application of a $0.7 \mathrm{~kg}$ load on the affected lower limb side at

Table 1. Study flow chart

\begin{tabular}{|c|c|c|}
\hline \multicolumn{3}{|c|}{ Screening of children with hemiparesis $(\mathrm{N}=15)$} \\
\hline $\mathrm{N}=10$ met $\mathrm{I}$ & teria & $\mathrm{N}=05$ were excluded \\
\hline \multicolumn{3}{|c|}{ Baseline recording of balance and angular parameters of gait (no additional load) } \\
\hline \multicolumn{3}{|c|}{ Group A } \\
\hline Recording of outcome measure & Affected side lower limb & Non affected side lower limb \\
\hline Ankle joint & $0.7 \mathrm{~kg}$ & $0.7 \mathrm{~kg}$ \\
\hline Knee joint & $0.7 \mathrm{~kg}$ & $0.7 \mathrm{~kg}$ \\
\hline \multicolumn{3}{|c|}{ Group B } \\
\hline Recording of outcome measure & Affected side lower limb & Non affected side lower limb \\
\hline Ankle joint & $1.1 \mathrm{~kg}$ & $1.1 \mathrm{~kg}$ \\
\hline Knee joint & $1.1 \mathrm{~kg}$ & $1.1 \mathrm{~kg}$ \\
\hline
\end{tabular}

Data was recorded and analysis was done 


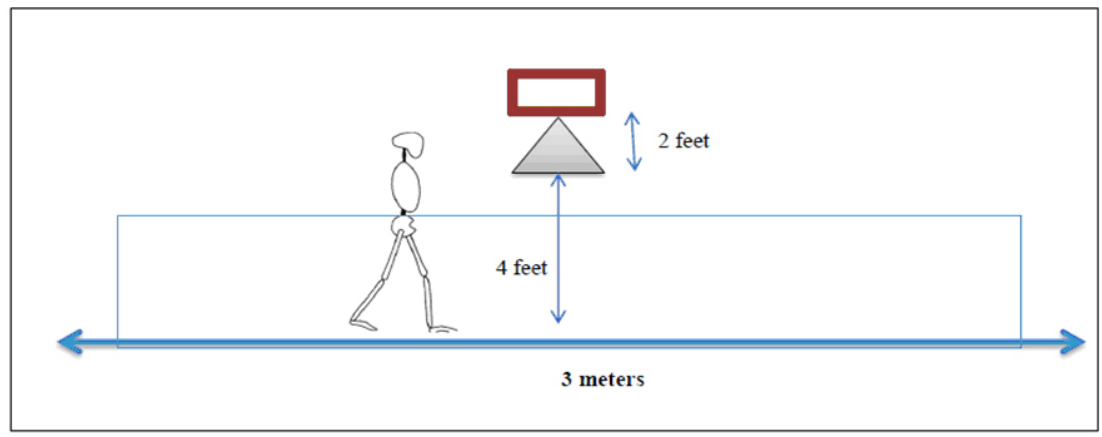

Figure 1. Camera and walk-way set up

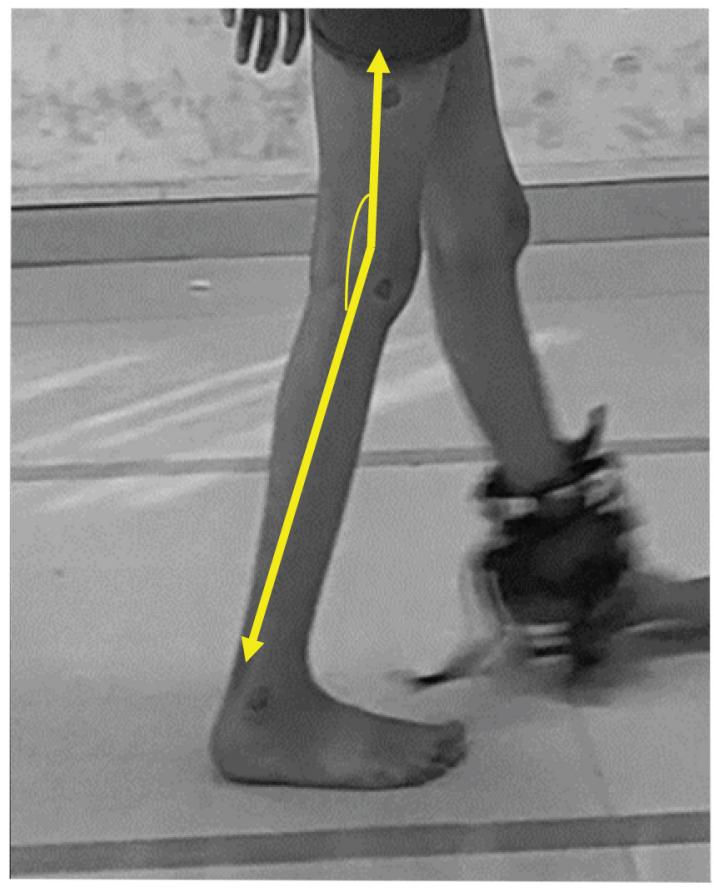

A) Knee joint angle measurement

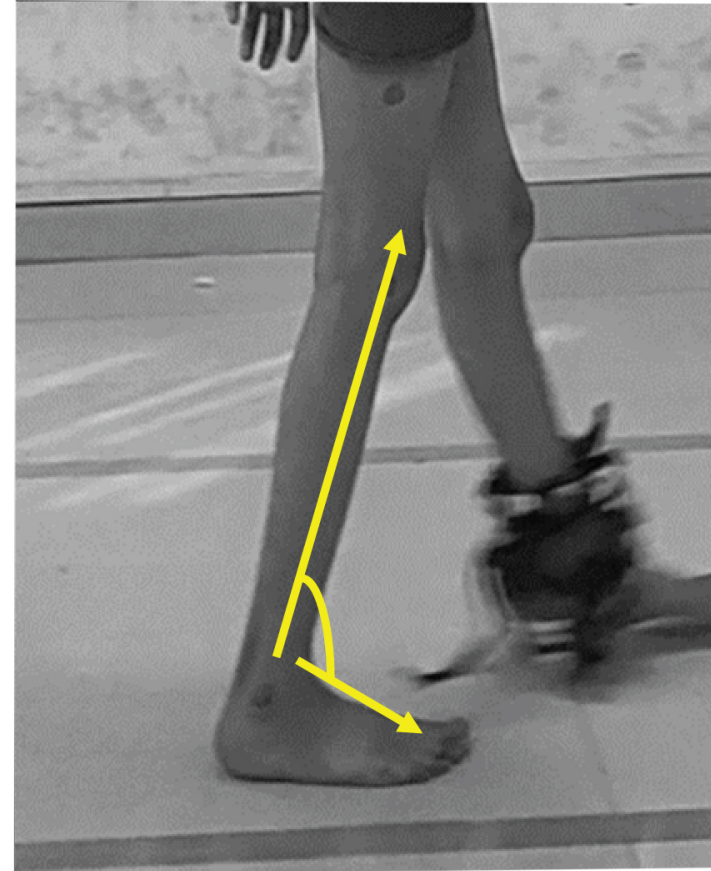

B) Ankle joint angle measurement

Figure 2. Measurement of Knee and Ankle joint angles during gait

the knee joint. The same procedure was carried out where an additional load was applied on the non-affected side lower limb at the ankle and knee joint respectively and participants were made to walk. Likewise, in Group B an additional load of $1.1 \mathrm{~kg}$ was used and the procedure remained the same as in group A where load is applied on the affected side followed by the non-affected side lower limb over the ankle and knee joint respectively. Three trials of all activities were video recorded and average knee joint and ankle joint angles were measured and documented (Figure 2).

Balance component: all 14 functional tasks was performed by the participants using an additional load of $0.7 \mathrm{~kg}$ in group A and $1.1 \mathrm{~kg}$ in group B. The additional load was applied on the affected side lower limb at the ankle and knee joint respectively followed by the load applied on the non-affected side lower limb and their performance was recorded. The Pediatric Balance Scale score and performance were recorded.

\section{Outcome measure}

Gait analysis included angular parameters of the following phases: the heel strike/contact phase where heel of leading extremity strikes the ground, the heel-off phase when the heel of the reference extremity leaves the ground, toe-off phase when the toe of the reference foot leaves the ground, the acceleration phase when the toes leaves the ground until maximum knee joint flexion is reached, and the deceleration phase when there is tibial advancement (vertical position of tibia) to achieve full knee joint extension in preparation for initial contact. Analysis of foot-flat and midstance phases was not considered as these phases 
were based on force shift and weight bearing whereas the mid-swing phase was more dynamic in nature. The angle formed between hip-knee-ankle and knee-ankle-foot markers was considered as the knee joint and ankle joint angles respectively. Video recordings of the procedure were uploaded to Kinovea (0.8.15) software and angular parameters of gait were analysed. Angles of knee and ankle joint were analysed at heel contact, heel-off, toe-off, acceleration and deceleration phases of the gait cycle $[16,18]$.

Pediatric Balance Scale (PBS): The PBS was used to assess balance. It includes 14 activity based functional tasks relevant to everyday activities: Sitting to standing; Standing to sitting; Transfers; Standing unsupported; Sitting unsupported; Standing with eyes closed; Standing with feet together; Standing with one foot in front; Standing on one foot; Turning 360 degrees; Turning to look behind; Retrieving object from floor; Placing alternate foot on stool and Reaching forward with outstretched arm. All 14 tasks' scores were recorded on a scale of 0 to 4 points. The maximum total score was 56 [13, 17, 47].

\section{Statistical analysis}

The data obtained were analysed using SPSS 24. Normality of the data was computed using the Shapiro-Wilk test. For normally distributed data, the paired t test was carried out and for data which did not follow a normal distribution the Wilcoxon signed rank test was used for analysis. The level of significance was considered as 0.05 .

\section{Results}

The effect of additional loaded weight on gait parameter angles and balance was recorded in 10 hemiparetic children. The total sample was stratified into 2 chronological age groups: group A (4-8 years) and group B (9-12 years). The mean age and BMI of group A were $6.2 \pm 1.5$ years and 16.5 $\pm 1.7 \mathrm{~kg} / \mathrm{m}^{2}$ whereas for group B the values were $10.8 \pm 1.3$ years and $19.9 \pm 1.5$ respectively. There were 4 participants, 2 males and 2 females in group A (younger) and 6 participants, 4 males and 2 females in group B (older) (Table 2).

Table 2. Demographic information of participants

\begin{tabular}{lcc}
\hline Variables & Group A (4-8 years) Mean \pm SD & Group B (9-12 years) Mean \pm SD \\
\hline Age $[\mathrm{yr}]$ & $6.2 \pm 1.5$ & $10.8 \pm 1.3$ \\
Height $[\mathrm{m}]$ & $1.3 \pm 0.1$ & $1.4 \pm 0.2$ \\
Weight $[\mathrm{kg}]$ & $25.7 \pm 5.5$ & $34 \pm 3.4$ \\
Body Mass Index $\left[\mathrm{kg} / \mathrm{m}^{2}\right]$ & $16.5 \pm 1.7$ & $19.9 \pm 1.5$ \\
Gender (N) Total: 10 & 4 & 6 \\
Male: 6 & 2 & 4 \\
Female: 4 & 2 & 2 \\
\hline
\end{tabular}

Table 3. Comparison of knee and ankle joint angles between additional load and no load at initial contact phase of affected leg during gait cycle

\begin{tabular}{|c|c|c|c|c|c|c|}
\hline \multirow{2}{*}{ Variables } & \multicolumn{3}{|c|}{ Knee joint angles (degree) } & \multicolumn{3}{|c|}{ Ankle joint angles (degree) } \\
\hline & Mean difference \pm SD & t value & $\mathrm{p}$ value & Mean difference $\pm \mathrm{SD}$ & t value & $\mathrm{p}$ value \\
\hline \multicolumn{7}{|c|}{ Group A (4-8 years) } \\
\hline $0.7 \mathrm{~kg}$ AFA & $-0.25 \pm 6.5$ & -0.07 & 0.94 & $2.75 \pm 1.70^{*}$ & 2.55 & 0.04 \\
\hline $0.7 \mathrm{~kg}$ NFA & $-4.25 \pm 10.62$ & -0.80 & 0.48 & $2.25 \pm 2.36$ & 2.78 & 0.15 \\
\hline $0.7 \mathrm{~kg}$ AFK & $-1.25 \pm 7.80$ & -0.32 & 0.77 & $5 \pm 4.76$ & 1.66 & 0.12 \\
\hline $0.7 \mathrm{~kg}$ NFK & $-4.25 \pm 9.46$ & -0.89 & 0.43 & $3.25 \pm 1.50^{*}$ & -0.54 & 0.02 \\
\hline \multicolumn{7}{|c|}{ Group B (9-12 years) } \\
\hline $1.1 \mathrm{~kg} \mathrm{AFA}$ & $11.00 \pm 5.09 *$ & 5.28 & $<0.001$ & $-3.16 \pm 15.43$ & 2.09 & 0.63 \\
\hline $1.1 \mathrm{~kg} \mathrm{NFA}$ & $13.33 \pm 13.79$ & 2.36 & 0.06 & $-1.83 \pm 17.47$ & -0.56 & 0.80 \\
\hline $1.1 \mathrm{~kg} \mathrm{AFK}$ & $9.66 \pm 13.03$ & 1.81 & 0.12 & $-1.50 \pm 12.40$ & 0.05 & 0.77 \\
\hline $1.1 \mathrm{~kg} \mathrm{NFK}$ & $11.66 \pm 11.67 *$ & 2.44 & 0.05 & $-9.00 \pm 15.17$ & -1.03 & 0.20 \\
\hline
\end{tabular}

$*_{-}$p $<0.05 ;$ AFA - Affected side ankle; NFA - Non-affected side ankle; AFK - Affected side Knee; NFK - Non-affected side Knee 
Table 4. Comparison of knee and ankle joint angles between additional load and no load at heel-off phase of affected leg during gait cycle

\begin{tabular}{|c|c|c|c|c|c|c|}
\hline \multirow{2}{*}{ Variables } & \multicolumn{3}{|c|}{ Knee joint angles (degree) } & \multicolumn{3}{|c|}{ Ankle joint angles (degree) } \\
\hline & Mean diff \pm SD & $\mathrm{t}$ value & $\mathrm{p}$ value & Mean diff \pm SD & $\mathrm{t}$ value & $\mathrm{p}$ value \\
\hline \multicolumn{7}{|c|}{ Group A (4-8 years) } \\
\hline $0.7 \mathrm{~kg} \mathrm{AFA}$ & $-10.0 \pm 5.35^{*}$ & -3.73 & 0.03 & $6.80 \pm 4.69$ & 2.55 & 0.08 \\
\hline $0.7 \mathrm{~kg}$ NFA & $-10.25 \pm 3.86^{*}$ & -5.30 & 0.01 & $10.50 \pm 7.54$ & 2.78 & 0.06 \\
\hline $0.7 \mathrm{~kg} \mathrm{AFK}$ & $-11.50 \pm 11.67$ & -1.97 & 0.14 & $6.25 \pm 7.50$ & 1.66 & 0.19 \\
\hline $0.7 \mathrm{~kg} \mathrm{NFK}$ & $-13.00 \pm 8.28^{*}$ & -3.13 & 0.05 & $-2.50 \pm 9.25$ & -0.54 & 0.62 \\
\hline \multicolumn{7}{|c|}{ Group B (9-12 years) } \\
\hline $1.1 \mathrm{~kg} \mathrm{AFA}$ & $0.166 \pm 6.04$ & 0.06 & 0.94 & $12.50 \pm 14.62$ & 2.09 & 0.09 \\
\hline $1.1 \mathrm{~kg} \mathrm{NFA}$ & $1.00 \pm 9.69$ & 0.25 & 0.81 & $-2.16 \pm 9.45$ & -0.56 & 0.59 \\
\hline $1.1 \mathrm{~kg}$ AFK & $2.33 \pm 10.34$ & 0.55 & 0.60 & $0.166 \pm 7.27$ & 0.05 & 0.95 \\
\hline $1.1 \mathrm{~kg} \mathrm{NFK}$ & $-2.83 \pm 12.18$ & -0.56 & 0.59 & $-3.50 \pm 8.26$ & -1.03 & 0.34 \\
\hline
\end{tabular}

* $-\mathrm{p}<0.05$; AFA - Affected side ankle; NFA - Non-affected side ankle; AFK - Affected side Knee; NFK - Non-affected side Knee

Table 5. Comparison of knee and ankle joint angles between additional load and no load at toe-off of affected leg during gait cycle

\begin{tabular}{|c|c|c|c|c|c|c|}
\hline \multirow{2}{*}{ Variables } & \multicolumn{3}{|c|}{ Knee joint angles (degree) } & \multicolumn{3}{|c|}{ Ankle joint angles (degree) } \\
\hline & Mean diff \pm SD & $\mathrm{t}$ value & $\mathrm{p}$ value & Mean diff \pm SD & t value & $\mathrm{p}$ value \\
\hline \multicolumn{7}{|c|}{ Group A (4-8 years) } \\
\hline $0.7 \mathrm{~kg}$ AFA & $-5.00 \pm 6.78$ & -1.47 & 0.23 & $4.00 \pm 2.94$ & 2.71 & 0.07 \\
\hline $0.7 \mathrm{~kg}$ NFA & $-8.75 \pm 9.74$ & -1.79 & 0.17 & $2.25 \pm 12.57$ & 0.35 & 0.74 \\
\hline $0.7 \mathrm{~kg}$ AFK & $-10.25 \pm 6.89 *$ & -2.97 & 0.05 & $4.25 \pm 6.39$ & 1.32 & 0.27 \\
\hline $0.7 \mathrm{~kg}$ NFK & $-21.00 \pm 6.63 *$ & -6.33 & $<0.001$ & $2.25 \pm 11.32$ & 0.39 & 0.71 \\
\hline \multicolumn{7}{|c|}{ Group B (9-12 years) } \\
\hline $1.1 \mathrm{~kg} \mathrm{AFA}$ & $-2.00 \pm 10.84$ & -0.45 & 0.67 & $-3.33 \pm 3.77$ & -2.16 & 0.08 \\
\hline $1.1 \mathrm{~kg} \mathrm{NFA}$ & $-5.83 \pm 14.81$ & -0.96 & 0.37 & $0.50 \pm 18.68$ & 0.06 & 0.95 \\
\hline $1.1 \mathrm{~kg}$ AFK & $-1.83 \pm 19.31$ & -0.23 & 0.82 & $6.00 \pm 13.35$ & 1.10 & 0.32 \\
\hline $1.1 \mathrm{~kg} \mathrm{NFK}$ & $-8.00 \pm 9.25$ & -2.11 & 0.08 & $2.16 \pm 12.27$ & 0.43 & 0.68 \\
\hline
\end{tabular}

AFA - Affected side ankle; NFA - Non-affected side ankle; AFK - Affected side Knee; NFK - Non-affected side Knee

In the initial contact phase there was a statistically significant difference in ankle joint angle on application of $0.7 \mathrm{~kg}$ weight over the affected lower limb at the ankle joint $(\mathrm{p}<0.001)$ and non-affected lower limb at the knee joint $(\mathrm{p}<0.001)$ in group A. Group B demonstrated a statistically significant difference in knee joint angles on application of a $1.1 \mathrm{~kg}$ load over the affected lower limb at the ankle joint $(p<0.001)$ and non-affected lower limb at the knee joint $(\mathrm{p}<0.001)$ (Table 3$)$.
In the heel-off phase, group A demonstrated a statistically significant difference in knee joint angles on application of a $0.7 \mathrm{~kg}$ load on both affected and non-affected lower limbs at the ankle joint and over the non-affected knee joint ( $\mathrm{p}<0.001$ respectively) (Table 4$)$.

In the toe-off phase, group A demonstrated a statistically significant difference in knee joint angles on application of a $0.7 \mathrm{~kg}$ load on both affected and non-affected lower limbs at the knee joint $(\mathrm{p}<0.001)$ (Table 5). 
Table 6. Comparison of knee and ankle joint angles between additional load and no load at acceleration of affected leg during gait cycle

\begin{tabular}{|c|c|c|c|c|c|c|}
\hline \multirow{2}{*}{ Variables } & \multicolumn{3}{|c|}{ Knee joint angles (degree) } & \multicolumn{3}{|c|}{ Ankle joint angles (degree) } \\
\hline & Mean diff $\pm \mathrm{SD}$ & t value & $\mathrm{p}$ value & Mean diff $\pm \mathrm{SD}$ & t value & $\mathrm{p}$ value \\
\hline \multicolumn{7}{|c|}{ Group A (4-8 years) } \\
\hline $0.7 \mathrm{~kg} \mathrm{AFA}$ & $-1.75 \pm 4.92$ & -0.71 & 0.52 & $10.50 \pm 9.00$ & 2.33 & 0.10 \\
\hline $0.7 \mathrm{~kg}$ NFA & $6.00 \pm 16.63$ & 0.72 & 0.52 & $0.00 \pm 12.67$ & 0.00 & 1.00 \\
\hline $0.7 \mathrm{~kg} \mathrm{AFK}$ & $2.25 \pm 11.23$ & 0.40 & 0.71 & $6.25 \pm 12.03$ & 1.03 & 0.37 \\
\hline $0.7 \mathrm{~kg}$ NFK & $-6.25 \pm 3.30$ & -3.78 & $0.03 *$ & $-1.00 \pm 12.67$ & -0.15 & 0.88 \\
\hline \multicolumn{7}{|c|}{ Group B (9-12 years) } \\
\hline $1.1 \mathrm{~kg} \mathrm{AFA}$ & $-3.33 \pm 5.68$ & -1.43 & 0.21 & $13.33 \pm 13.67$ & 2.38 & 0.06 \\
\hline $1.1 \mathrm{~kg} \mathrm{NFA}$ & $-3.00 \pm 10.17$ & -0.72 & 0.50 & $5.00 \pm 14.50$ & 0.84 & 0.43 \\
\hline $1.1 \mathrm{~kg}$ AFK & $1.50 \pm 10.03$ & 0.36 & 0.72 & $6.16 \pm 13.76$ & 1.09 & 0.32 \\
\hline $1.1 \mathrm{~kg} \mathrm{NFK}$ & $-1.50 \pm 4.80$ & -0.76 & 0.47 & $2.00 \pm 12.24$ & 0.40 & 0.70 \\
\hline
\end{tabular}

AFA - Affected side ankle; NFA - Non-affected side ankle; AFK - Affected side Knee; NFK - Non-affected side Knee

Table 7. Comparison of knee and ankle joint angles between additional load and no load at deceleration of affected leg during gait cycle

\begin{tabular}{|c|c|c|c|c|c|c|}
\hline \multirow{2}{*}{ Variables } & \multicolumn{3}{|c|}{ Knee joint angles (degree) } & \multicolumn{3}{|c|}{ Ankle joint angles (degree) } \\
\hline & Mean diff \pm SD & t value & $\mathrm{p}$ value & Mean diff \pm SD & t value & $\mathrm{p}$ value \\
\hline \multicolumn{7}{|c|}{ Group A (4-8 years) } \\
\hline $0.7 \mathrm{~kg}$ AFA & $-5.50 \pm 5.06$ & -2.17 & 0.11 & $-3.50 \pm 6.24$ & -1.12 & 0.34 \\
\hline $0.7 \mathrm{~kg} \mathrm{NFA}$ & $-8.00 \pm 2.70$ & -5.90 & $0.01 *$ & $-0.50 \pm 4.50$ & -0.22 & 0.83 \\
\hline $0.7 \mathrm{~kg}$ AFK & $-7.00 \pm 2.58$ & -5.42 & $0.01 *$ & $-4.25 \pm 3.20$ & -2.65 & 0.07 \\
\hline $0.7 \mathrm{~kg}$ NFK & $-10.00 \pm 5.94$ & -0.54 & $0.04 *$ & $-10.75 \pm 8.99$ & -2.39 & 0.09 \\
\hline \multicolumn{7}{|c|}{ Group B (9-12 years) } \\
\hline $1.1 \mathrm{~kg} \mathrm{AFA}$ & $3.33 \pm 3.07$ & 2.65 & $0.04 *$ & $1.50 \pm 3.27$ & 1.12 & 0.31 \\
\hline $1.1 \mathrm{~kg} \mathrm{NFA}$ & $3.66 \pm 8.84$ & 1.01 & 0.35 & $3.00 \pm 14.38$ & 0.51 & 0.63 \\
\hline $1.1 \mathrm{~kg} \mathrm{AFK}$ & $0.16 \pm 6.43$ & 0.06 & 0.95 & $2.83 \pm 13.10$ & 0.53 & 0.61 \\
\hline $1.1 \mathrm{~kg}$ NFK & $-7.50 \pm 13.66$ & -1.34 & 0.23 & $1.16 \pm 12.28$ & 0.23 & 0.82 \\
\hline
\end{tabular}

AFA - Affected side ankle; NFA - Non-affected side ankle; AFK - Affected side Knee; NFK - Non-affected side Knee

In the acceleration phase, group A demonstrated a statistically significant difference in knee joint angles on application of a $0.7 \mathrm{~kg}$ load on the non-affected lower limb at the knee joint $(\mathrm{p}<0.001)$ (Table 6).

In the deceleration phase, group A demonstrated a statistically significant difference in knee joint angles on application of a $0.7 \mathrm{~kg}$ load on the non-affected lower limb at ankle and knee joints and over the affected knee joint $(\mathrm{p}<0.001$ respectively). Group B demonstrated a statistically significant difference in knee joint angles on application of a $1.1 \mathrm{~kg}$ load over the affected lower limb at ankle joint $(\mathrm{p}<0.001)$ (Table 7).

This study reported a statistically significant difference in Pediatric Balance Scale score with application of $0.7 \mathrm{~kg}$ and $1.1 \mathrm{~kg}$ weights on knee and ankle joints of the affected and non-affected lower limb in group $A(p=0.05)$ and group $B(p=0.02)$ respectively (Table 8$)$. 
Table 8. Comparison of pre post scores of pediatric balance scale between additional load and no load over the joints

\begin{tabular}{lccccc}
\hline Group A (4-8 years) & Z value & $\mathrm{p}$ value & Group B (9-12 years) & $\mathrm{Z}$ value & $\mathrm{p}$ value \\
\hline $0.7 \mathrm{~kg}$ AFA & -1.89 & 0.05 & $1.1 \mathrm{~kg}$ AFA & -2.23 & 0.02 \\
$0.7 \mathrm{~kg}$ NFA & -1.89 & 0.05 & $1.1 \mathrm{~kg} \mathrm{NFA}$ & -2.23 & 0.02 \\
$0.7 \mathrm{~kg} \mathrm{AFK}$ & -1.89 & 0.05 & $1.1 \mathrm{~kg} \mathrm{AFK}$ & -2.23 & 0.02 \\
$0.7 \mathrm{~kg} \mathrm{NFK}$ & -1.89 & 0.05 & $1.1 \mathrm{~kg} \mathrm{NFK}$ & -2.23 & 0.02 \\
\hline
\end{tabular}

AFA - Affected side ankle; NFA - Non-affected side ankle; AFK - Affected side Knee; NFK - Non-affected side Knee

\section{Discussion}

The present study explored the effect of additional load on angular parameters during gait and balance in hemiparetic children.

Angular parameters at initial contact phase: There was a significant improvement at the ankle joint angle of the affected lower limb on application of an additional load on the affected side over the ankle joint and non-affected side over the knee joint in the younger participant group. The application of load over the affected side on the ankle joint must have increased load sensitive receptors' response, which created an instable ankle joint balanced by the elicited spinal reflex resulting in activation of ankle dorsiflexor muscle and angle variability towards normal. A study by $\mathrm{Wu}$ and Schmit [45] also suggests that a loaded response at the ankle joint and release of the spinal reflex during locomotion in spinal cord injury patients. Normal gait is bipedal and biphasic in nature with equal contribution of both lower limbs during the entire process. Children with hemiparesis have gait disturbance due to uneven distribution of bodyweight and limbs leading to weakness of muscles involved in gait and difficulty in foot clearance during gait. Improvement in ankle angle on applying weight over the non-affected side knee joint at initial contact could be because additional load to the non-affected side at the knee joint must have added to pre-existing disturbed weight body weight distribution that must have created increase demand on the affected limb to attain the state of equilibrium and compensate for discrepancy that must have activated the ankle dorsiflexor muscle and showed variability to in angle towards normal. A similar study with use of an angular wedge insole on the unaffected limb showed improvement in functional gait in post-stroke patients $[5,6,46,47]$.

Completed knee extension is required at initial contact of normal gait. In our study there was no significant change in knee joint angle on application of load at initial contact, suggesting that there was no overcompensation in the lower limb joint, thereby suggesting that the applied load is appropriate in young children with hemiparesis.

Angular parameter in heel-off and toe-off phase: There was a significant improvement in the knee joint angle of the affected lower limb on application of additional load on the affected side over the ankle joint and the nonaffected side over the ankle and knee joint in the younger participant group. During the heel-off phase the forefoot is in contact with the ground and the weight is over the distal segment of the tibia. Additional load over the affected side ankle joint along with segmented weight over the tibia together created a torque response at the ankle joint where the ankle joint acted as a pulley between the tibial end and forefoot. The longer effort arm created a mechanical advantage rebound effect at the ankle joint, causing variation at affected side knee joint angle towards normal [27]. Additional load over the non-affected side at the knee and ankle joint must have generated increased muscle activity and increased load acceptance on the affected side limb in order to overcome and maintain the equilibrium state during dynamic gait activity leading to variation in knee joint angles towards normal [49]. A study by Savin et al. [34] showed that activation of contralateral lower limb muscles on application of resisted diagonal movement is due to the proprioceptive neuromuscular facilitation principle of irradiation. In our study the applied load on the nonaffected lower limb acted as resistance that activated the contralateral limb during the activity. Also, studies have shown that strength resistance training has shown improvement in gait function in post-stroke patients. Studies have shown that high intensity strength training improves muscle strength and functional performance and reduces disability in post-stroke patients [29, 43-46].

In the older group of participants, improvement was seen in the affected side knee joint angle during initial contact of gait on application of load over the non-affected side knee joint and affected side ankle joint and no improvement in ankle joint angle. In normal children aged 8 years and above gait maturity was attained that is similar to normal adults [15]. Older group hemiparesis participants were also of similar age; there must be strong faulty 
neural circuit adaptation and abnormal gait muscle activation and with additional load over the limb must have caused an increased compensatory mechanism causing no changes at the terminal joint (ankle joint angle) that led to disturbance in the above joint. Hip and knee flexors were over activated foot-ground clearance, causing abnormal angular variation at the knee joint.

Angular parameters at acceleration phase: There was a significant improvement of the knee joint angle of the affected side lower limb on application of additional load on the non-affected side over the knee joint in the younger participant group during the acceleration phase. Increased knee flexor muscle activity could be a result of additional load that acted as resistance applied on the contralateral limb and phasic dynamic force must have resulted in Brunnstrom lower limb associated reaction causing increased muscular activity in the ipsilateral limb [37]. A study by Shin and Lee [40] using a jacket with weights in stroke patients showed increased muscle activity in order to maintain dynamic balance during gait. Our study also produced similar results with application of additional load on the non-affected lower limb during the acceleration phase; the non-affected leg is in contact with the ground whereas the affected leg has entered the swing phase. Applied additional load increases hip abductors' and pelvic stabiliser muscle activity to minimize and maintain the centre of gravity during the phase of the ipsilateral limb. In normal gait during the swing phase ankle dorsiflexion along with knee flexion movement is necessary for foot clearance, absence of which will create an abnormal and short duration swing phase. Application of additional load is speculated to have more hip-knee muscular activity for ground clearance of the ipsilateral limb, thereby causing variation in the acceleration phase at the knee joint angle of the affected leg towards normal. Our study also found no significant improvement in ankle joint angles during the acceleration phase, suggesting increased muscular activity of joint above. Similar results were obtained by Roche et al. [24] and Lam et al. [36], stating that reduced ankle dorsiflexors are compensated by hip flexor muscles during the swing phase of gait among adult stroke individuals and incomplete spinal cord injury patient.

Angular parameters at deceleration phase: There was a significant improvement in knee joint angle of the affected lower limb on application of additional load on the affected side over the knee joint and the non-affected side over the ankle and knee joint during the deceleration phase in the younger participant group. Improvement with application of additional load over the affected side knee joint must be because properties of load and gravitational force acting on the loaded affected limb could have activated quadriceps muscle causing variation in the knee joint angle towards normal. Similar results were obtained that suggest gravity plays a vital role in human gait by increasing phasic muscle work and modulating walking speed $[4,34,39]$. Improvement with application of additional load over the non-affected side knee and ankle joint could be because during the deceleration phase the nonaffected leg is in the heel-off stance phase whereas the affected side is not in contact with the ground. Increased load at the push-off phase of the non-affected leg made increased muscle activity of quadriceps and hip flexors of the affected side to achieve early heel contact and attain double limb support in order to maintain balance. The deceleration phase is a dynamic, progressive and transient phase. Transition from swing to stance causes loaded body weight transfer towards the affected limb and change of centre of gravity, producing increased activation of the affected lower limb mechanoreceptors, thereby increase muscular activity of the affected leg leading to variation in knee joint angle of the affected leg towards normal. The study by Paschalis et al. [30] suggests that alteration in knee extensors can cause variation in gait biomechanics. In our study, overactivation of knee extensors due to increased sensory input played a major role in gait variation $[3,30]$.

In children above 8 years, maturation of lower limb growth and body mass distribution act as a key factor for gait variability. Increased limb weight along with additional load must have increased load arm, leading to increased gravitational force acting on the affected lower limb which must have caused knee joint angle variation in the deceleration phase of gait in older participants. A study suggests that limb maturity, mass and nutritional status of child can cause variation in spatiotemporal gait characteristics in childhood and adolescents [15].

Balance component: It was observed that children with hemiparesis reported significant improvement in balance with application of additional load in both the groups separately. Standing posture in hemiparetic children is characterized by poor large amplitude postural sway control and decreased muscle activation. This leads to a disproportionate reaction in postural sway, thereby causing balance disturbance. Application of additional load over ankle and knee joints is speculated to stimulate mechanoreceptors and proprioception receptors around the joint, thereby improving joint position sense and movement force and providing joint stability. Also, additional loading over joints may have triggered the central nervous system to exhibit normal timing and intensity of muscle activation in the lower extremity during task performance that helped in gaining more stability and improved balance. A similar result was obtained by Shina et al. [20] with improvement by adding weighted jackets in adult stroke patients. In our study, additional load caused unexpected load over the joints that imposed change in body position, centre of mass (COM) shifts 
and muscle activation to correct disturbance and regain stability $[14,33]$.

\section{Limitations}

1) The hip joint also plays a vital role in the gait cycle, but in our study angular parameter of the hip joint was not considered for analysis. 2) Use of a time-based functional dynamic task scale could have elaborated the balance component in detail $[8,19]$. Future studies can consider additional load in therapy and explore its effect. Also, further study is required to explore the scope in terms of additional load and its effects on angular parameters of gait in older children with hemiparesis.

\section{Conclusions}

Our present study confirms that application of additional load of $0.7 \mathrm{~kg}$ over the non-affected leg knee joint is able to produce significant changes in ankle joint angles at initial contact and knee joint angles at heel-off, toe-off, acceleration and deceleration phases of gait and balance in the younger participant group, whereas application of additional load of $1.1 \mathrm{~kg}$ over the affected leg at the ankle joint showed significant improvement in knee joint angles at initial and deceleration phases of gait.

Additional load over knee and ankle joints of affected and non-affected legs showed more improvement in angular parameter during gait and balance in younger children with hemiparesis than older ones, as they present an immature form of gait that can be modified, corrected and brought back to a normal angle.

Clinical implication: It can be recommended that applying an additional load of $0.7 \mathrm{~kg}$ can aid in improving angular parameters of gait and balance in younger children with hemiparesis. Older children need an additional load of $1.1 \mathrm{~kg}$ to produce significant changes in balance and knee joint angles in initial contact and deceleration phases of gait.

\section{Conflict of interest: Authors state no conflict of interest.}

\section{References}

1. Arányi Z., Rösler K.M. (2002) Effort-induced mirror movements. Exp. Brain Res., 145(1): 76-82.

2. Armand S., Decoulon G., Bonnefoy-Mazure A. (2016) Gait analysis in children with cerebral palsy. EFORT Open Rev., 1(12): 448-460. DOI: 10.1302/2058-5241 .1 .000052 .

3. Brunner R., Rutz E. (2013) Biomechanics and muscle function during gait. J. Child Orthop., 7(5): 367-371. DOI: $10.1007 / \mathrm{s} 11832-013-0508-5$.
4. Cavagna G.A., Willems P.A., Heglund N.C. (2000) The Role of Gravity in Human Walking: Pendular Energy Exchange, External Work and Optimal Speed. J. Physiol., 5(28): 657-668.

5. Chaudhuri S., Aruin A.S. (2000) The effect of shoe lifts on static and dynamic postural control in individuals with hemiparesis. Arch. Phys. Med. Rehabil., 81: 1498-1503,

6. Chen C.-H., Lin K.-H., Lu T.-W., Chai H.-M., Chen H.-L., Tang P.-F., Hu M.-H. (2010) Immediate effect of lateralwedged insole on stance and ambulation after stroke. Am. J. Phys. Med. Rehabil., 89: 48-55.

7. Cooper J., Majnemer A., Rosenblatt B., Birnbaum R. (1995) The determination of sensory deficits in children with hemiplegic cerebral palsy. J. Child Neurol., 10(4): 300-309.

8. de AC Duarte N., Grecco L.A., Franco R.C., Zanon N., Oliveira C.S. (2014) Correlation between Pediatric Balance Scale and functional test in children with cerebral palsy. J. Phys. Ther. Sci., 26(6): 849-853.

9. de Oliveira C.B., de Medeiros Í.R., Frota N.A., Greters M.E., Conforto A.B. (2008) Balance control in hemiparetic stroke patients: main tools for evaluation. J. Rehabil. Res. Dev., 45(8): 1215-1227.

10. Degelaen M., De Borre L., Kerckhofs E., De Meirleir L., Buyl R., Cheron G., Dan B. (2013) Influence of botulinum toxin therapy on postural control and lower limb intersegmental coordination in children with spastic cerebral palsy. Toxins, 5(1): 93-105.

11. Fatone S., Stine R. (2015) Capturing Quality Clinical Videos for Two-Dimensional Motion Analysis. The American Academy of Orthotists and Prosthetists, 27(1): 27-32.

12. Ferdjallah M., Harris G.F., Smith P., Wertsch J.J. (2002) Analysis of postural control synergies during quiet standing in healthy children and children with cerebral palsy. Clin. Biomech., 17(3): 203-210.

13. Franjoine M.R., Gunther J.S., Taylor M.J. (2003) Pediatric balance scale: a modified version of the berg balance scale for the school-age child with mild to moderate motor impairment. Pediatr. Phys. Ther., 15(2): 114-128.

14. Freyler K., Gollhofer A., Colin R., Brüderlin U., Ritzmann R. (2015) Reactive balance control in response to perturbation in unilateral stance: interaction effects of direction, displacement and velocity on compensatory neuromuscular and kinematic responses. PLoS ONE. 10(12): 111-114.

15. Froehle A.W., Nahhas R.W., Sherwood R.J., Duren D.L. (2013) Age-related changes in spatiotemporal characteristics of gait accompany ongoing lower limb linear growth in late childhood and early adolescence. Gait Posture, 38(1): 14-19.

16. Guzmán-Valdivia C.H., Blanco-Ortega A., Oliver-Salazar M.A., Carrera-Escobedo J.L. (2013) Therapeutic mo- 
tion analysis of lower limbs using Kinovea. Int. J. Soft Comput. Eng., 3(2): 359-365.

17. Her J.G., Woo J.H., Ko J. (2012) Reliability of the pediatric balance scale in the assessment of the children with cerebral palsy. J. Phys. Ther. Sci., 24(4): 301-305.

18. Hisham N.A., Nazri A.F., Madete J., Herawati L., Mahmud J. (2017) Measuring ankle angle and analysis of walking gait using Kinovea. International Medical Device and Technology Conference, pp. 247-250.

19. Jeon Y.J., Kim G.M. (2016) Comparison of the psychometric properties of two balance scales in children with cerebral palsy. J. Phys. Ther. Sci., 28(12): 3432-3434.

20. Jung T., Lee D., Charalambous C., Vrongistinos K. (2010) The influence of applying additional weight to the affected leg on gait patterns during aquatic treadmill walking in people poststroke. Arch. Phys. Med. Rehabil., 91(1): 129-136.

21. Kaul S. (2000) Cerebrovascular diseases in children. Indian Pediatrics, 37: 159-171.

22. Kenis-Coskun O., Giray E., Eren B., Ozkok O., KaradagSaygi E. (2016) Evaluation of postural stability in children with hemiplegic cerebral palsy. J. Phys. Ther. Sci., 28(5): 1398-1402.

23. Kułak W., Sobaniec W., Kuzia J.Ś., Boćkowski L. (2006) Neurophysiologic and neuroimaging studies of brain plasticity in children with spastic cerebral palsy. Exp, Neurol., 198(1): 4-11.

24. Lam T., Wirz M., Lünenburger L., Dietz V. (2008) Swing phase resistance enhances flexor muscle activity during treadmill locomotion in incomplete spinal cord injury. Neurorehabil. Neural Repair, 22(5): 438-446.

25. Michelini A., Eshraghi A., Andrysek J. (2020) Two-dimensional video gait analysis: A systematic review of reliability, validity, and best practice considerations. Prosthetics and Orthotics International, 44(4): 245-262.

26. Mukherjee A., Chakravarty A. (2010) Spasticity mechanisms - for the clinician. Front. Neurol., 1: 149.

27. Nuckols R.W., Sawicki G.S. (2020) Impact of elastic ankle exoskeleton stiffness on neuromechanics and energetics of human walking across multiple speeds. J. Neuroeng. Rehabil., 17(1): 75.

28. Olney S., Eng J. (2012) Gait, Joint structure and function $5^{\text {th }}$ edition, India, Jaypee brothers' medical publishers, pp. 525-564.

29. Ouellette M.M., LeBrasseur N.K., Bean J.F., Phillips E., Stein J., Frontera W.R., Fielding R.A. (2004) Highintensity resistance training improves muscle strength, self-reported function, and disability in long-term stroke survivors. Stroke, 35(6): 1404-1409.

30. Paschalis V., Giakas G., Baltzopoulos V., Jamurtas A.Z., Theoharis V., Kotzamanidis C., Koutedakis Y. (2007) The effects of muscle damage following eccentric exercise on gait biomechanics. Gait Posture, 25(2): 236-242.
31. Pieter M., Leen V.G., Lynn B.O., Marije G., Hans H.W., Erwin A., Herman B., Guy M., Paul D.C., Els O.E., Kaat D. (2016) Children with Spastic Cerebral Palsy Experience Difficulties Adjusting Their Gait Pattern to Weight Added to the Waist, While Typically Developing Children Do Not. Front. Hum. Neurosci., 1: 657-667.

32. Prakash C., Gupta K., Mittal A., Kumar R., Laxmi V. (2015) Passive marker based optical system for gait kinematics for lower extremity. Procedia Comput. Sci., 45: 176-185.

33. Ritzmann R., Lee K., Krause A., Gollhofer A., Freyler K. (2018) Stimulus prediction and postural reaction: Phasespecific modulation of soleus H-reflexes is related to changes in joint kinematics and segmental strategy in perturbed upright stance. Front. Integr. Neurosci., 12: 62.

34. Roche N., Bonnyaud C., Geiger M., Bussel B., Bensmail D. (2015) Relationship between hip flexion and ankle dorsiflexion during swing phase in chronic stroke patients. Clin. Biomech., 30(3): 219-225.

35. Ross S.A., Rice C., Behren K.C., Meyer A., Alexander R., Murfin S. (2014) Reliability of sagittal plane hip, knee, and ankle joint angles from a single frame of video data using the GAITRite camera system, 1: 53-60.

36. Savin D.N., Tseng S.C., Morton S.M. (2010) A bilateral adaptation during locomotion following a unilaterally-applied resistance to swing in non-disabled adults. J. Neurophysiol., 104(6): 3600-3611. DOI: 10.1152/ jn.00633.2010.

37. Sawner K., Brunnstrom S., Vigne J.M. (1992) Brunnstrom's Movement Therapy in Hemiplegia: A Neurophysiological Approach. Lippincott Williams \& Wilkins; Subsequent edition.

38. Schmitz T., O’Sullivan S. (2014) Examination of Coordination and Balance. Physical Rehabilitation. India. Jaypee Brothers' medical publishers, (pp-226).

39. Segers V. (2006) A biomechanical analysis of the realization of actual human gait transition. [Ghent, Belgium]: Ghent University. Faculty of Medicine and Health Sciences.

40. Shin S.H., Lee M.Y. (2014) Effect of gait training with additional weight on balance and gait in stroke patients. Phys. Ther. Rehabil. Sci., 3(1): 55-62.

41. Silva D.B., Dias L.B., Pfeifer L.I. (2016) Reliability of the Gross Motor Function Classification System Expanded and Revised (GMFCS E \& R) among students and health professionals in Brazil. Fisioterapia e Pesquisa, 23(2): 142-147.

42. Stacy A.S, Ashley N.M, Jacob E.R, Susan A.S. (2017) Two-Dimensional Video Analysis is Comparable to $3 \mathrm{~d}$ Motion Capture in Lower Extremity Movement Assessment. Int. J. Sports Phys. Ther., 12 (2):163-72.

43. Steenbergen B., Gordon A.M. (2006) Activity limitation in hemiplegic cerebral palsy: evidence for disor- 
ders in motor planning. Dev. Med. Child Neurol., 48(9): 780-783.

44. Sullivan K., Klassen T., Mulroy S. (2006) Combined task-specific training and strengthening effects on locomotor recovery post-stroke: a case study. J. Neurol. Phys. Ther., 30(3):130-141.

46. Weiss A., Suzuki T., Bean J., Fielding R.A. (2000) High intensity strength training improves strength and functional performance after stroke. Am. J. Phys. Med. Rehabil., 79: 369-376.

47. Wu M., Schmit B.D. (2006) Spastic reflexes triggered by ankle load release in human spinal cord injury. J. Neurophysiol., 96(6): 2941-2950.

48. Yi S.H., Hwang J.H., Kim S.J., Kwon J-Y. (2012) Validity of pediatric balance scales in children with spastic cerebral palsy. Neuropediatrics, 43(06): 307-313.
49. Yu W.H., Liu W.Y., Wong A.M., Wang T.C., Li Y.C., Lien H.Y. (2015) Effect of forced use of the lower extremity on gait performance and mobility of post-acute stroke patients. J. Phys. Ther. Sci., 27(2): 421-425.

50. Zonta M.B., Ramalho Júnior A., Camargo R.M., Dias F.H., Santos L.H. (2010) Two-dimensional analysis of gait asymmetry in spastic hemiplegia. Einstein, 8(3): 343-349.

\section{Received 03.04.2019 \\ Accepted 10.12.2020}

(c) University of Physical Education, Warsaw, Poland 